\title{
EDITORIAL
}

\section{Envisioning toward Building a Fairer and Healthier World: A Joint Effort}

\author{
Subhash C Parija ${ }^{1}$, Saurabh R Shrivastava ${ }^{2}$ \\ SBV Journal of Basic, Clinical and Applied Health Science (2021): 10.5005/jp-journals-10082-03109
}

It is a known fact that our world is an unequal one, with some sections of the community having better access to health care and welfare measures, while there are many other sections of the community who are deprived of all the basic and essential health care. ${ }^{1}$ In fact, disparity exists in terms of education, occupation, income, housing standards, food security, gender inequality, etc., making the overall scenario quite complex. These inequalities and disparities account for unnecessary suffering, failure to prevent the development of avoidable illnesses, impairment in the quality of life of people, physical-mental-social consequences, and even premature death. $^{2}$

The emergence of the coronavirus disease-2019 (COVID-19) pandemic has further complicated the issue, predominantly because the available resources are now directed toward the effective containment of the pandemic, which has jeopardized the delivery of essential healthcare services, especially in lowand middle-income nations. The World Health Organization has come out with five priority areas to create a fairer and healthier world for everyone. ${ }^{1}$ The first and foremost priority considering the current developments is to ensure that nations get equitable access to technology and logistics (viz. vaccines, personal protective equipment, drugs, diagnostic kit, etc.) essential for the effective containment of the COVID-19 pandemic through a well-defined mechanism. ${ }^{1,2}$

The next priority is to augment investment for the strengthening of the primary health care so that we can improve the lives of marginalized sections of the community. ${ }^{1,3}$ This calls for the need for the international welfare agencies and donor agencies to provide assistance to the financially weak nations to take targeted interventions to improve the overall healthcare delivery system, and thereby produce better health outcomes and improved efficiency. ${ }^{1,2}$ Subsequently, we should aim for safeguarding the health and social protection by building a strong network to prevent disruptions in the welfare measures, regardless of the existing or novel public health emergencies. ${ }^{1,2}$

At present, the available estimates suggest that four-fifths of the world's population living in extreme poverty are residing in rural settings, which $80 \%$ of the rural people lack access to drinking water provision. ${ }^{1}$ Thus, there is a strong need to prioritize the delivery of basic social service measures (viz. transport facilities, water and sanitation provisions, healthy housing, recreational
1Department of Community Medicine, Vice-Chancellor, Sri Balaji Vidyapeeth, Puducherry, India

${ }^{2}$ Department of Community Medicine, Shri Sathya Sai Medical College and Research Institute, Sri Balaji Vidyapeeth, Puducherry, India

Corresponding Author: Saurabh Shrivastava, Department of Community Medicine, Shri Sathya Sai Medical College and Research Institute, Sri Balaji Vidyapeeth, Puducherry, India, e-mail: drshrishri2008@gmail.com

How to cite this article: Parija SC, Shrivastava SR. Envisioning toward Building a Fairer and Healthier World: A Joint Effort. J Basic Clin Appl Health Sci 2021;4(1):1-1.

Source of support: Nil

Conflict of interest: None

options, etc.), so that people can maintain a good quality of life. ${ }^{1,3}$ Further, as not much can be attained unless we have access to good quality data, there is a big-time need to strengthen data and health information systems. The comprehensive nature of the data will aid the policymakers to understand the gravity of the problem and thereby take evidence-based and well-informed decisions. ${ }^{1-3}$

To summarize, in the context of global vision to create a fairer and healthier world, a lot needs to be done to not only make progress but even sustain the gains achieved so far, and to adopt a multisectoral approach, wherein all the concerned stakeholders work in alignment and collaboration to make the world a healthy place for everyone.

\section{References}

1. World Health Organization. WHO urges countries to build a fairer, healthier world post-COVID-19; 2021. Available from: https:// www.who.int/news/item/06-04-2021-who-urges-countries-tobuild-a-fairer-healthier-world-post-covid-19 [Last accessed on 29 Apr 2021].

2. Al-Mandhari A, Marmot M, Ghaffar A, et al. COVID-19 pandemic: a unique opportunity to 'build back fairer' and reduce health inequities in the Eastern Mediterranean Region. East Mediterr Health J 2021;27(3):217-219. DOI: 10.26719/2021.27.3.217.

3. Ismail SJ, Tunis MC, Zhao L, et al. Navigating inequities: a roadmap out of the pandemic. BMJ Glob Health 2021;6(1):e004087. DOI: 10.1136/bmjgh-2020-004087. 